\title{
Pengaruh Kepatuhan dan Ketepatan Waktu Minum Obat Terhadap Tekanan Darah Pasien Hipertensi Primer
}

\author{
Baiq Leny Nopitasari, Wirawan Adikusuma, Nurul Qiyaam, Ayu Fatmala \\ Program Studi DIII Farmasi, Universitas Muhammadiyah Mataram, baiqleny.nopitasari@gmail.com
}

\section{INFO ARTIKEL}

\section{Riwayat Artikel:}

Diterima:12-01-2019

Disetujui: 29-01-2019

\section{Kata Kunci:}

Hipertensi primer Amlodipin Tekanan Darah Kepatuhan Ketepatan waktu

\begin{abstract}
ABSTRAK
Abstrak: Salah satu faktor yang mempengaruhi tekanan darah pasien hipertensi yaitu tingkat kepatuhan dan waktu minum obat yang tepat. Tingkat kepatuhan penderita dalam minum obat merupakan salah satu faktor yang menentukan keberhasilan terapi, terutama untuk penyakit hipertensi. Penelitian ini bertujuan untuk mengetahui pengaruh kepatuhan dan ketepatan waktu minum obat terhadap tekanan darah pasien hipertensi primer. Penelitian ini menggunakan desain kuasi-eksperimental dengan mengambil data pasien secara prospektif selama periode Juli-Oktober 2018. Populasi yang digunakan adalah pasien yang menjalani rawat jalan di poliklinik jantung dan poliklinik penyakit dalam RSUD Provinsi NTB, sedangkan sampel penelitian adalah pasien yang menjalani rawat jalan di poliklinik jantung dan poliklinik penyakit dalam RSUD Provinsi NTB dengan diagnosa utama hipertensi dan diberikan terapi tunggal amlodipin $5 \mathrm{mg}$ selama periode penelitian. Data yang didapatkan selanjutnya akan dianalisis statistik menggunakan program SPSS versi 16.0. Hasil penelitian menunjukkan bahwa waktu pemberian amlodipin $5 \mathrm{mg}$ yang digunakan 1 kali sehari pada pagi hari (sebelum pukul 12.00) dengan malam hari (setelah pukul 18.00) tidak berbeda signifikan ( $P$ > $0,05)$ terhadap penurunan tekanan darah (sistole dan diastole) pasien hipertensi primer rawat jalan. Sedangkan terdapat pengaruh yang signifikan antara kepatuhan minum obat terhadap perubahan tekanan darah sistole $(P<0,05)$. Namun, tidak berpengaruh signifikan antara kepatuhan minum obat terhadap tekanan darah diastole $(P>0,05)$.
\end{abstract}

Abstract. One of the factors that influence blood pressure in hypertensive patients is the level of adherence and the time to take the right medication. The level of patient compliance in taking medicine is one of the factors that determine the success of therapy, especially for hypertension. This study aims to determine the effect of compliance and timeliness of taking medication against the blood pressure of primary hypertensive patients. This study used a quasi-experimental design by taking patient data prospectively during the period JulyOctober 2018. The population used was outpatient patients at the heart polyclinic and the internal medicine clinic at the NTB Provincial Hospital, while the study sample was outpatient patients at heart polyclinic and internal medicine polyclinic at the Provincial Hospital of NTB with the primary diagnosis of hypertension and given single therapy amlodipine $5 \mathrm{mg}$ during the study period. The data obtained will then be analyzed statistics using the SPSS version 16.0 program. The results showed that the time of administration of amlodipine $5 \mathrm{mg}$ used once a day in the morning (before 12.00) with the evening (after 18.00) did not differ significantly $(P>0.05)$ on the decrease in blood pressure (systole and diastole) of the patient outpatient primary hypertension. Whereas there was a significant effect between medication adherence to changes in systolic blood pressure $(P<0.05)$. However, there was no significant effect between medication adherence to diastolic blood pressure $(P>0.05)$. 


\section{A. LATAR BELAKANG}

World Health Organization (WHO) menyatakan bahwa lebih dari satu milyar orang di dunia menderita hipertensi, dua per tiga diantaranya berada di negara berkembang yang berpenghasilan rendah sampai dengan sedang. Hipertensi telah mengakibatkan kematian sekitar 8 juta orang setiap tahun, 1,5 juta kematian terjadi di Asia Tenggara. Penyakit hipertensi merupakan peningkatan tekanan darah yang memberi gejala yang berlanjut untuk suatu target organ, seperti stroke untuk otak, penyakit jantung koroner untuk pembuluh darah jantung dan untuk otot jantung. Penyakit ini telah menjadi masalah utama dalam kesehatan masyarakat yang ada di Indonesia maupun di beberapa negara yang ada di dunia (Armilawaty, 2007). Menurut Data Riset Kesehatan Dasar (Riskesdas) 2013, menunjukkan bahwa 25,8\% penduduk Indonesia mengidap hipertensi dan mengalami kenaikan di tahun 2016 menjadi 32,4\%. Diperkirakan sekitar 80\% kenaikan kasus hipertensi pada tahun 2025 dari 639 juta kasus diperkirakan menjadi 1,5 milyar kasus. Prediksi ini didasarkan pada angka penderita hipertensi dan pertambahan penduduk saat ini.

Hipertensi merupakan penyakit seumur hidup yang tidak bisa disembuhkan secara permanen sehingga banyak pasien yang jenuh dan tidak patuh dalam pengobatan yang menyebabkan tidak terkontrolnya tekanan darah. Salah satu faktor yang mempengaruhi tekanan darah pasien hipertensi yaitu, tingkat kepatuhan dan waktu minum obat yang tepat. Tingkat kepatuhan penderita dalam minum obat merupakan salah satu faktor yang menentukan keberhasilan terapi, terutama untuk penyakit hipertensi. Adapun yang menjadi faktor penghalang yang mempengaruhi kepatuhan pasien yaitu lamanya terapi, komunikasi yang kurang baik antara pasien dan tenaga kesehatan, kurangnya informasi, keamanan, efek samping, biaya pengobatan dan faktor psikologis (Aronson, 2007). Menurut laporan World Health Organization (WHO) pada tahun 2003, kepatuhan rata-rata pasien pada terapi jangka panjang terhadap penyakit kronis di negara maju sebesar 50\% dan di negara berkembang diperkirakan akan lebih rendah. Sebuah meta analisis mengenai hubungan antara penggunaan obat terhadap kejadian mortalitas yang berasal dari 21 penelitian menunjukkan kepatuhan terhadap penggunaan obat berhubungan positif dengan hasil pengobatan (WHO, 2003).

Telah banyak dilakukan penelitian tentang obat-obat anti-hipertensi. Salah satunya adalah penelitian waktu pemberian amlodipin $5 \mathrm{mg}$ sebagai anti hipertensi tunggal yang digunakan 1 kali sehari pada pagi hari dengan malam hari berpengaruh secara signifikan terhadap penurunan tekanan darah (sistole dan diastole) pasien (Karlina, 2014). Sedangkan menurut Roland
Asmar (2010) tidak ada perbedaan penurunan tekanan darah pada penggunaan pagi dan malam hari dalam profil tekanan darah 24 jam terhadap golongan penghambat kanal kalsium. Penelitian lain menyatakan bahwa penggunaan amlodipin pada pagi hari (7 am) memberikan penurunan tekanan darah yang lebih besar daripada penggunaan amlodipin pada malam hari (9 pm) (Qiu, 2003) sedangkan menurut Lemmer (2012) tidak ada perbedaan penurunan tekanan darah pada penggunaan pagi dan malam hari dalam profil tekanan darah 24 jam terhadap golongan penghambat kanal kalsium.

Penggunaan amlodipin di Rumah Sakit Umum Daerah Provinsi Nusa Tenggara Barat (RSUD Provinsi NTB) untuk pasien hipertensi bervariasi yaitu menggunakan $5 \mathrm{mg}$ dan $10 \mathrm{mg}$. Di RSUD Provinsi NTB belum ada ketentuan dalam penggunaannya, sebagian dokter memberikan terapi pagi dan ada juga yang memberikan terapi pada malam hari. Berdasarkan latar belakang tersebut peneliti ingin meneliti tentang pengaruh kepatuhan dan ketepatan waktu minum obat terhadap tekanan darah pasien hipertensi primer. Dari hasil penelitian ini diharapkan dapat diketahui waktu yang paling tepat untuk meminum amlodipin agar dapat mengontrol tekanan darah dengan baik.

\section{B. METODE PENELITIAN}

Penelitian dilakukan di poliklinik jantung dan poliklinik penyakit dalam RSUD Provinsi NTB selama bulan Juli-Oktober 2018. Penelitian ini menggunakan desain kuasi eksperimental dengan mengambil data pasien secara prospektif.

Populasi penelitian adalah pasien yang menjalani rawat jalan di poliklinik jantung dan poliklinik penyakit dalam RSUD Provinsi NTB. Sampel penelitian adalah pasien yang menjalani rawat jalan di poliklinik jantung dan poliklinik penyakit dalam RSUD Provinsi NTB dengan diagnosa utama hipertensi dan diberikan terapi tunggal amlodipin $5 \mathrm{mg}$ selama periode penelitian. Dalam penelitian ini penulis menggunakan teknik pengambilan sampel dengan menggunakan total sampling karena jumlah populasi yang kurang dan semua populasi dijadikan sampel penelitian.

Kriteria inklusi berupa pasien berjenis kelamin lakilaki dan perempuan yang berusia 46-80 tahun dengan diagnose hipertensi primer yang menggunakan obat hipertensi tunggal amlodipin $5 \mathrm{mg}$. Sedangkan kriteria eksklusi berupa ibu hamil dan menyusui, pasien yang menggunakan obat anti hipertensi lain dan mengalami komplikasi, serta pasien yang tidak kontrol kembali selama priode penelitian.

Variabel bebas dalam penelitian ini adalah waktu pemberian amlodipin kepada pasien (pagi sebelum jam 12.0o WITA atau malam hari setelah jam 18.0o WITA) dan kepatuhan minum obat yang diukur dengan metode Piil count. Sedangkan variabel terikat dalam penelitian 
ini adalah selisih tekanan darah sistole dan diastole pasien sbelum diterapi dengan tekanan darah sistole dan diastole pasien setelah melakukan terapi amlodipin.

Analisis statistik dan pengolahan data dilakukan dengan menggunakan program SPSS versi 16.0.

\section{HASIL DAN PEMBAHASAN}

Penelitian ini sudah mendapatkan persetujuan etik dari Komite Etik RSUD Provinsi NTB dengan No : 070.1/22/KEP/2017. Jumlah pasien yang memenuhi kriteria inklusi dan eksklusi untuk penelitian ini sebanyak 15 pasien untuk amlodipin $5 \mathrm{mg}$ yang diminum pada pagi hari dan 15 pasien untuk amlodipin $5 \mathrm{mg}$ yang diminum pada malam hari. Waktu penelitian 7 hari setelah minum obat amlodipin $5 \mathrm{mg}$, sehingga diharapkan amlodipin telah mencapai kadar puncak dalam darah dan dapat bekerja secara maksimal dalam penurunan tekanan darah.

\section{Ketepatan Waktu Minum Obat Terhadap Tekanan Darah}

Data tekanan darah sistole dan diastole pagi maupun malam hari dapat dilihat pada tabel 1 dan 2 dibawah ini.

TABEL 1.

Perbedaan Waktu Minum Obat Terhadap Tekanan Darah Sistole

\begin{tabular}{|c|c|c|c|}
\hline Kelompok & Mean \pm SD & $\begin{array}{c}\text { P.value } \\
\text { a }\end{array}$ & P.value b \\
\hline Pre pagi & $157,47 \pm 17,39$ & $0,000^{*}$ & \multirow{3}{*}{0,610} \\
\hline Post pagi & $130,93 \pm 13,84$ & & \\
\hline $\begin{array}{l}\text { Pre malam } \\
\text { Post malam }\end{array}$ & $\begin{array}{l}160,13 \pm 21,06 \\
133,87 \pm 12,95\end{array}$ & $0,000^{*}$ & \\
\hline
\end{tabular}

TABEL 2.

Perbedaan Waktu Minum Obat Terhadap Tekanan Darah Diastole

\begin{tabular}{|c|c|c|c|}
\hline Kelompok & Mean \pm SD & $\begin{array}{c}\text { P.value } \\
\text { a }\end{array}$ & P.value b \\
\hline $\begin{array}{l}\text { Pre pagi } \\
\text { Post pagi }\end{array}$ & $\begin{array}{l}83,86 \pm 16,49 \\
77,60 \pm 8,86\end{array}$ & 079 & \\
\hline $\begin{array}{l}\text { Pre malam } \\
\text { Post malam }\end{array}$ & $\begin{array}{l}86,66 \pm 12,90 \\
78,00 \pm 5,60\end{array}$ & $0,004^{*}$ & 0,740 \\
\hline
\end{tabular}

Data tabel 1 dapat dilihat bahwa terdapat perbedaan yang tidak signifikan antara tekanan darah sistole pada pasien yang menggunakan obat amlodipin pagi dengan amlodipin malam hari dengan nilai $\mathrm{P}=0,610$ (P > 0.05). Sama hal nya dengan data tabel 2 dapat dilihat bahwa terdapat perbedaan yang tidak signifikan antara tekanan darah diastole pada pasien yang menggunakan obat amlodipin pagi dengan amlodipin malam hari dengan nilai $\mathrm{P}=0,74(\mathrm{P}>$ 0.05).

Efektivitas terapi hipertensi dilihat dari penurunan tekanan darah. Efektivitas obat antihipertensi dibuktikan dengan tercapainya target terapi pada obat antihipertensi yang digunakan, tekanan darah sistole $<120$ dan tekanan darah diastole $<80$ (JNC VIII, 2014). Obat anti-hipertensi golongan penghambat kanal kalsium (amlodipin) menunjukkan perbedaan efektivitas jika diberikan pada waktu yang berbeda dan hasilnya berbeda antara penghambat kanal kalsium yang diberikan pagi hari dengan yang diberikan malam hari (Baraldo, 2008; Ohdo, 2010).

Hasil penelitian yang dilakukan di Rumah Sakit Umum Daerah Provinsi Nusa Tenggara Barat (RSUD Provinsi NTB) menyatakan terdapat perbedaan yang tidak signifikan antara tekanan darah sistole maupun diastole terhadap penurunan tekanan darah pada penggunaan amlodipin $5 \mathrm{mg}$ tunggal, yang artinya penggunaan obat amlodipin $5 \mathrm{mg}$ jika diminum pagi atau malam hari memberikan efek penurunan tekanan darah yang sama. Penelitian ini sama dengan penelitian dari Lemmer (2012) yang menyatakan tidak ada perbedaan yang signifikan antara penggunaan amlodipin selama $24 \mathrm{jam}$. Hal ini dapat disebabkan karena beberapa faktor antara lain, karakteristik pasien (penyakit penyerta dan farmakogenomik seperti umur, jenis kelamin, dan ras) yang digunakan dalam penelitian berbeda. Hal -hal di atas akan mempengaruhi kerja obat dalam tubuh sehingga akan memberikan hasil yang berbeda.

Hasil di atas berbeda dengan beberapa penelitian sebelumnya seperti penelitian yang dilakukan oleh Qiu (2003) yang menyatakan bahwa untuk menurunkan tekanan darah nokturnal, amlodipin lebih baik diberikan pada pagi hari daripada malam hari. Dan penelitian yang dilakukan oleh Karlina (2014) yang menyatakan bahwa penurunan tekanan darah (sistole dan diastole) pasien hipertensi primer rawat inap berpengaruh secara signifikan dengan hasil lebih besar bila amlodipin diberikan pada malam hari (setelah pukul 18.0o) daripada pagi hari (sebelum pukul 12.00).

Hal ini berkaitan dengan farmakologi yang dimana ritme sirkadian tekanan darah mencapai puncak pada pukul 6 hingga 10 pagi, kadar amlodipin dalam darah mendekati kadar maksimal (yaitu 55,8ng/mL, setelah diminum 6-12 jam) bila diminum pada malam hari (pukul 18.00) amlodipin dapat menurunkan tekanan darah tepat pada saat tekanan darah tersebut mencapai puncaknya. Sehingga pemberian amlodipin pada malam hari (setelah pukul 18.00) lebih menurunkan tekanan darah sistole dan diastole secara signifikan daripada amlodipin yang diberikan pada pagi hari (sebelum pukul 12.00) (Schachter, M., 2004).

\section{Kepatuhan Minum Obat Terhadap \\ Tekanan Darah}

Keuntungan dari metode pill count antara lain mudah, objektif, dan kuantitatif, sedangkan kerugiannya adalah dapat dengan mudah diubah oleh pasien (pill dumping). Untuk self-report 
mempunyai keuntungan antara lain singkat, mudah dihitung, dan sesuai untuk beberapa jenis pengobatan, sedangkan kerugiannya adalah bisa dimanipulasi oleh pasien (Osterberg et al, 2005).

Menurut laporan World Health Organization (WHO) pada tahun 2003, kepatuhan rata-rata pasien pada terapi jangka panjang terhadap penyakit kronis di negara maju sebesar 50\% dan di negara berkembang diperkirakan akan lebih rendah. Sebuah meta analisis mengenai hubungan antara penggunaan obat terhadap kejadian mortalitas yang berasal dari 21 penelitian menunjukkan kepatuhan terhadap penggunaan obat berhubungan positif dengan hasil pengobatan (WHO, 2003).

Pada penelitian ini metode analisi yang digunakan dalam menentukan pengaruh kepatuhan obat yaitu metode korelasional. Metode regresi linear adalah suatu uji hasil penelitian untuk mengetahui pengaruh antara satu atau beberapa variabel terhadap satu buah variabel tanpa ada upaya untuk mempengaruhi variabel tersebut sehingga tidak terdapat manipulasi variabel (Faenkel dan Wallen, 2008). Data kepatuhan minum obat dapat dilihat pada tabel 3 .

TABEL 3.

Analisis Regresi Linear antara Kepatuhan minum obat dan Tekanan Darah

\begin{tabular}{lcc}
\hline Kelompok & Korelasi & P value \\
\hline Sistole & 0,631 & $0,000^{*}$ \\
Diastole & 0,115 & 0,273 \\
\hline${ }^{*} P<0$, o5 : Korelasi, hubungan & kepatuan dengan \\
\multicolumn{4}{c}{ tekanan darah }
\end{tabular}

Data tabel 3 menyebutkan bahwa adanya pengaruh yang signifikan antara kepatuhan minum obat terhadap penurunan tekanan darah sistole karena $\mathrm{P}=0$,000 $(\mathrm{P}<0,05)$. Sedangkan pada tekanan darah diastole tidak berpengaruh signifikan karena $\mathrm{P}=0,273(\mathrm{P}>0,05)$. Dan data menunjukkan korelasi positif yang artinya semakin patuh pasien minum obat makan tekanan darah pasien dapat terkontrol dengan baik.

Hasil di atas dapat dikaitkan dengan hasil penelitian dari Chayanee Smantummkul (2014) yang menyatakan adanya pengaruh kepatuhan minum obat hipertensi terhadap perubahan tekanan darah. Ketidakpatuhan terhadap terapi merupakan kontributor utama gagalnya kontrol tekanan darah pada pasien hipertensi. Semakin tinggi tingkat ketidakpatuhan pasien akan sejalan dengan semakin tinggi risiko komplikasi.

\section{SIMPULAN DAN SARAN}

Kesimpulan dalam penelitian ini adalah waktu pemberian amlodipin $5 \mathrm{mg}$ yang digunakan 1 kali sehari pada pagi hari (sebelum pukul 12.00) dengan malam hari (setelah pukul 18.0o) terdapat perbedaan yang tidak signifikan $(\mathrm{P}>0,05)$ terhadap penurunan tekanan darah (sistole dan diastole) pasien hipertensi primer rawat jalan, serta terdapat pengaruh yang signifikan antara kepatuhan minum obat terhadap perubahan tekanan darah sistole $(\mathrm{P}<0,05)$ namun, tidak berpengaruh signifikan antara kepatuhan minum obat terhadap tekanan darah diastole $(\mathrm{P}>0,05)$.

Saran untuk penelitian selanjutnya adalah penelitian dengan jumlah subyek hipertensi yang lebih banyak, sehingga perkembangan tekanan darah pasien dapat benar-benar diamati, penelitian sebaiknya dilakukan dengan mengambil sampel pasien yang menjalani rawat inap sehingga tekanan darah dapat dikontrol 24 jam, dan pengukuran kepatuhan pasien selain dengan pill count sebaiknya dilakukan dengan pengukuran menggunakan kuisioner agar data kepatuhan yang didapat lebih akurat lagi.

\section{DAFTAR RUJUKAN}

[1] Aronson, J.K.,2007, Compliance, concordance, adherence, British Journal of Clinical Pharmacology, 63(4), pp.383384 .

[2] Armilawaty, 2007, Hipertensi dan Faktor Risikonya Dalam Kajian Epidemiologi, Bagian Epidemiologi FKM UNHAS 2007.

[3] Baraldo, M., 2008, The Influence of Circadian Rhythms on The Kinetics of Drugs in Human, Expert Opinion Drug Metabolism Toxicology4(2) : 175-192

[4] Departemen Kesehatan RI, 2006, Pedoman Surveilans : Epidemiologi Penyakit Jantung dan Pembuluh Darah. Jakarta: Direktorat pengendalian Penyakit Tidak Menular Departemen Kesehatan Republik Indonesia

[5] Departemen Kesehatan R.I., (2006), Pharmaceutical Care Untuk Penyakit Hipertensi, Jakarta : Departemen Kesehatan Republik Indonesia

[6] Dipiro, J.T, Talbert, R.L, Yee,G.C, Matzke, G.R, Wells, B.G, and Posey, L., 2008, Pharmocotherapy A Pathophysiologic Approach, 6th edition, McGraw-Hill, Chapter 15

[7] JNC-VIII. 2014. The Eight Report of the Joint National Committee. Hypertension Guidelines: An In-Depth Guide. Am J Manag Care

[8] Joint National Committeon Prevention, Detection, Evaluation, and Treatment of Hight Blood Pressure. The sixth of the joint National Committee on Prevention, Detection, Evaluation, and Treatment oh Hight Blood Pressure. National Institute of Hight Blood Pressure 2014.

[9] Karlina. 2014, Perbandingan Pengaruh Waktu Pemberian Amlodipin Pagi Versus Malam Terhadap Penurunan Tekanan Dararh Pasien Hipertensi Primer Rawat Inap Di Rumah Sakit Bethesda Yogyakarta, Tesis Universitas Gadjah Mada, Yogyakarta.

[10] Laurence, L.B., 2008, Goodm an \& Gilma's : $M$ anu al $P$ harmaco logy a nd Therapeutics. 7th Edition, McGraw Hill, 546-560

[11] Lemmer, B., 2012, The Importance of Biological Rhythms in Drug Treatment of Hypertension and Sex Dependent Modifications, Institute of Experimentaland Clinical Pharmacology and Toxicology, Ruprecht Karls University ofHeidelberg, Mannheim, Germany

[12] Ohdo, S., 2010, Chronopharmaceutics : Pharmaceutics Focused on Biological Rhythm. Biological Pharmacy. 33(2): 159-167

[13] Osterberg., Lars, Blashke., Terrence. (2005), Adherence to edication. The New England Journal of Medecine, 97, 353487 
[14] Qiu, Y.G, Chen, J.Z, Zhu, J.H, and Yao, X.Y., 2003, Differential Effects of Morning or Evening Dosing of Amlodipin on Circadian Blood Pressure And Heart Rate, Cardiovascular Drugs and Therapy.17; 335-341

[15] Riset Kesehatan Dasar, 2013, Pedoman Pewawancara Petugas Pengumpul Data. Jakarta : Badan Litbangkes, Depkes RI, 2013

[16] Roland Asmara, Philippe Gosseb, Ste' phane Quere' and Assya Achouba, 2010, Efficacy of morning and evening dosing of amlodipine/valsartan combination in hypertensive patients uncontrolled by $5 \mathrm{mg}$ of amlodipine,Clinical trials : Blood Pressure Monitoring 2011,Vol 16 No 2

[17] Schachter, M., 2004, Diurnal Rhythms, The ReninAngiotensin System and Antihypertensive Therapy, British Journal of Cardiology;11:4

[18] Vik, S.A. et al., 2005. Assessing Medication Adherence Among Older Persons in Community Settings. Can J Clin Pharmacol, 12(1), pp.5-9.

[19] Weber MA, Schiffrin EL, White WB, Mann S, Lindholm LH, Kenerson JG, et al. Clinical Practice Guidelines for the Maganement of Hypertension in the Community. A Statement by the American Society of Hypertension and the International Society of Hypertension. ASH paper. The Journal of Clinical Hypertension, 2013.

[20]World Health Organization. 2003. Adherence To LongTerm Therapies. Switzerland : World Health Organization 